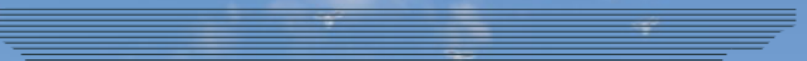

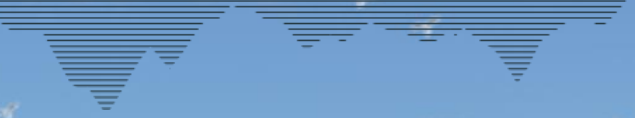

\title{
USING SCREEN-BASED VIRTUAL - REALITY LANDSCAPES TO PREPARE STUDENTS FOR THE FIELD
}

Jacqueline Houghton ${ }^{1}$, Annabeth Robinson², Clare Gordon'1, Geoff Lloyd ${ }^{1}$ and Dan Morgan1 ${ }^{1}$ School of Earth and Environment, University of Leeds, ${ }^{2}$ Leeds College of Art

www.see.leeds.ac.uk/virtual-landscapes/ 


\section{Virtual Landscapes}

- Create screen-based virtual reality environments.

- Built with Unity 3D.

- Enhance training students receive in preparation for fieldwork.

- Replicate aspects of the mapping experience - not a fieldwork replacement as they cannot teach key observational skills.
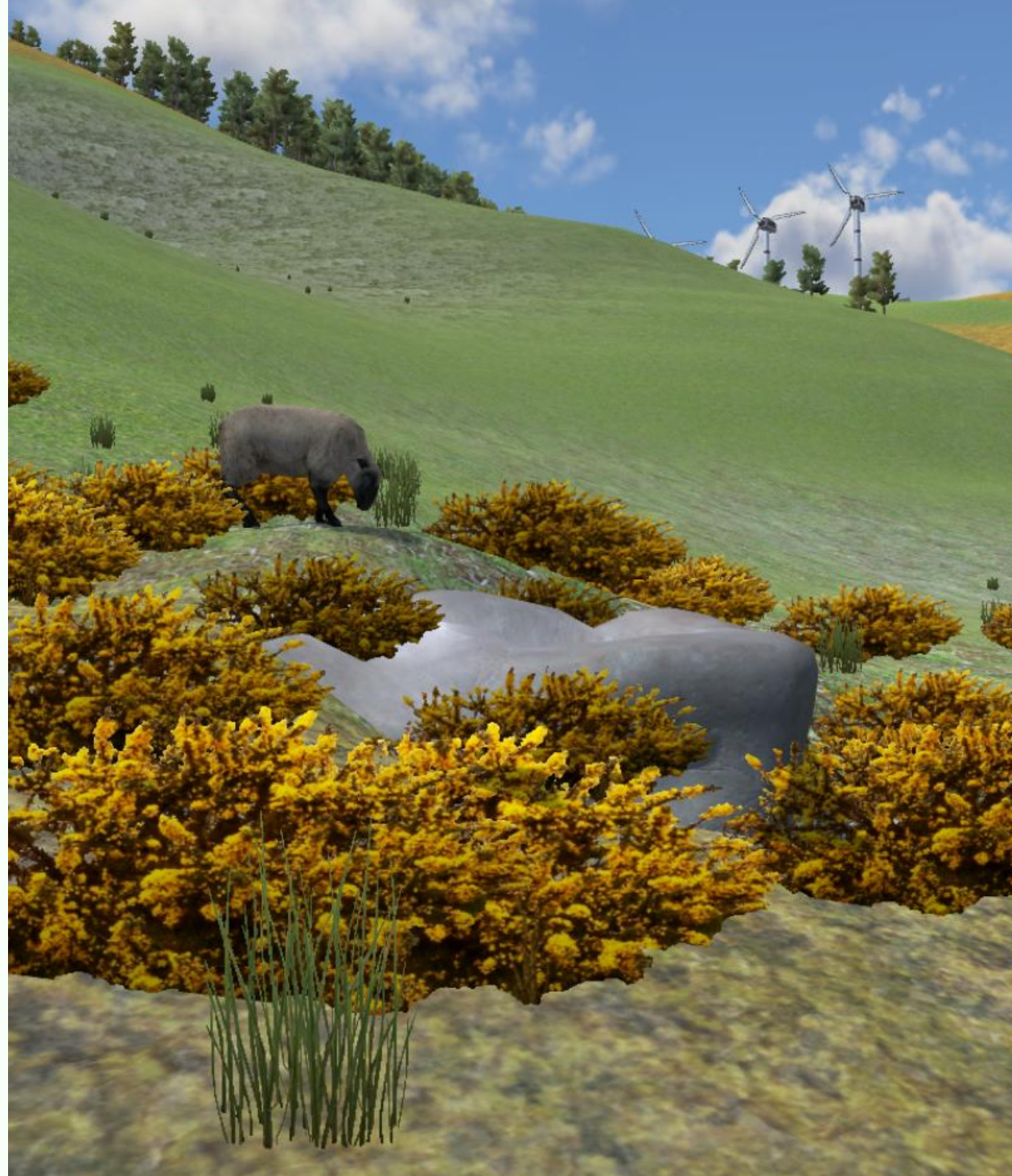


\section{Mapping \& Field Skills}

- Designed as in-class exercises with paper field slips and notebooks.

- Virtual landscapes populated with 'outcrops' with 'notebook' entries giving information on the rocks.

- "Three River Hills": original world, complex geology.

- "Lighthouse Bay": simple geology, better looking.

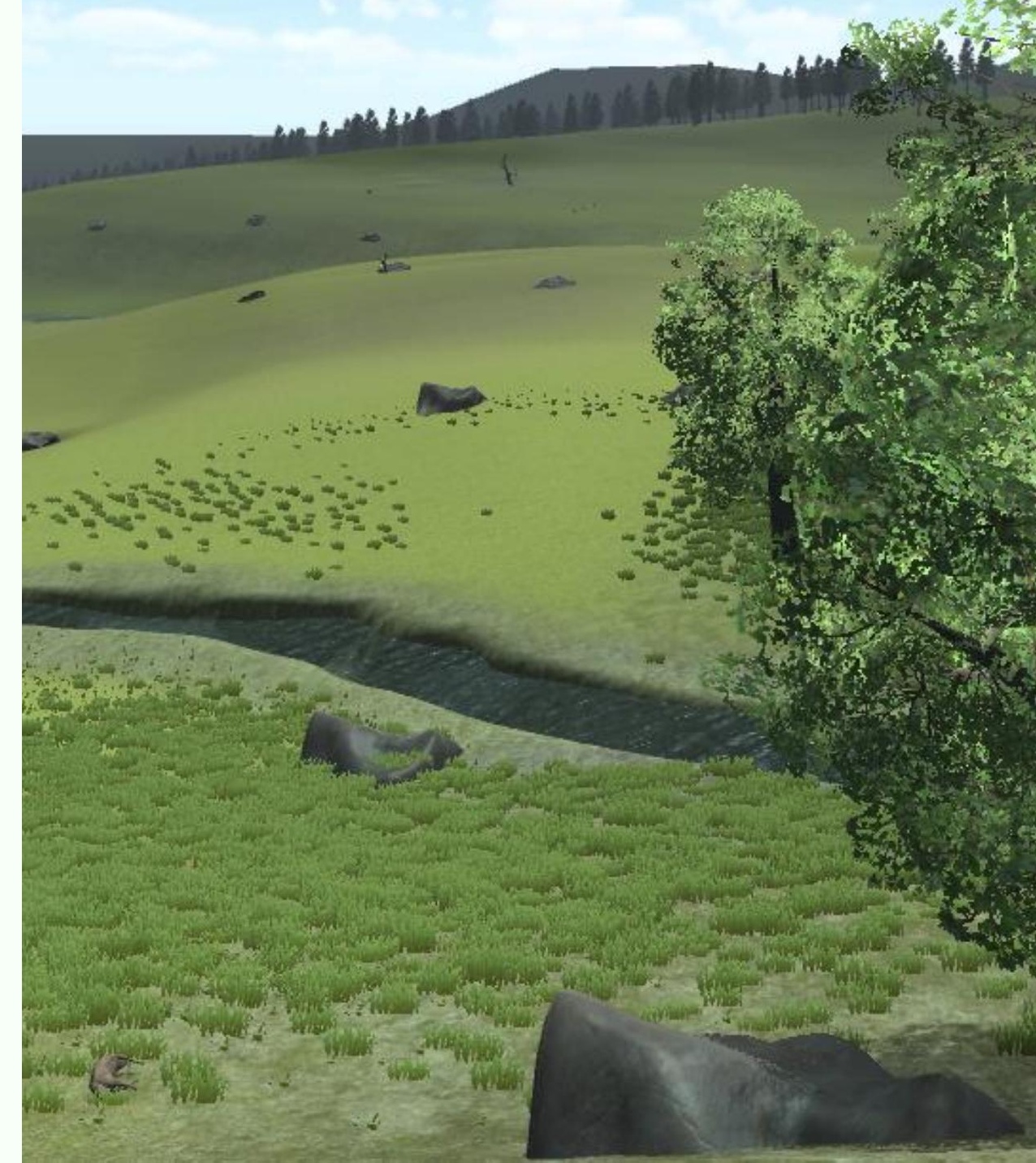


蘥

\section{UNIVERSITY OF LEEDS}

Virtual Landscapes Geoscience Education in Digital Environments

Virtual Training Environment

GeOLOGICAL MAPPING \& FIEID SKIILS

$\frac{1}{4}$
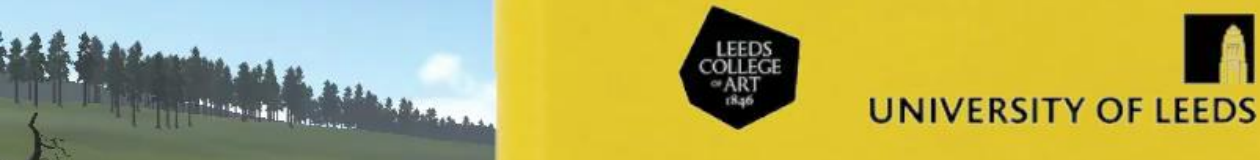

UNIVERSITY OF LEEDS
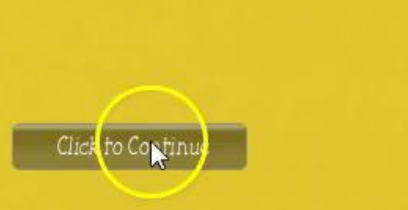

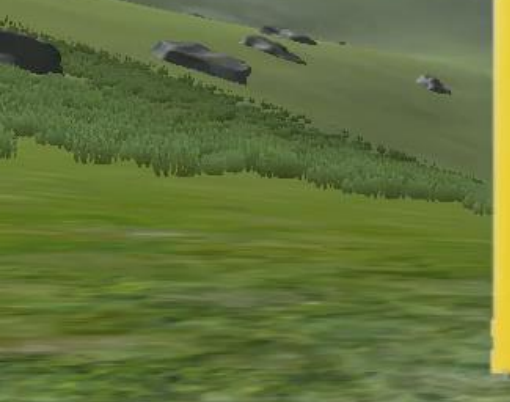

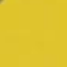

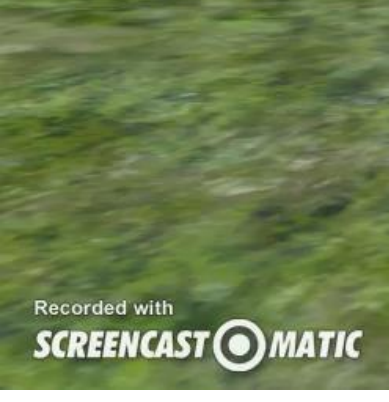

\section{wWw.see.leeds.ac.uk/virtual-landscapes/}




\section{Mapping \& Field Skills}

- Using grid references.

- Plotting outcrops and readings on a field slip.

- Interpret data and decision making skills.

- Thinking in 3D.

- Constructing a geological map, cross section and stratigraphic column from own data. 


\section{Use in the Class} Room

- Easier to focus on learning and teaching the skills in a classroom than in the field.

- Students made the same mistakes they make when learning in the field.

- "Outcrop capture" - get 'em on the map fast; worry about the geology later.

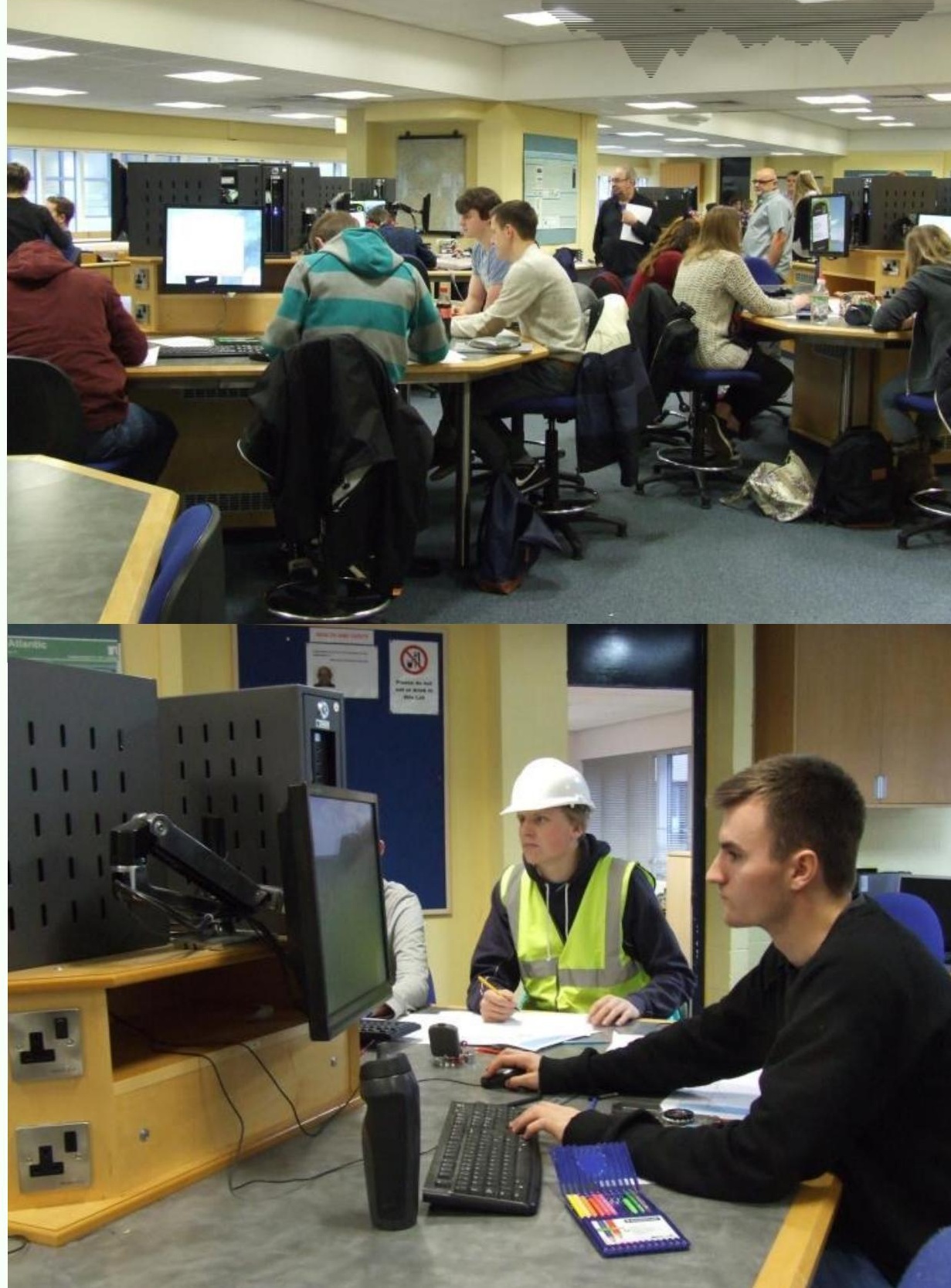




\section{Results in the field}

- Staff reported time saved in the field as basic skills already embedded and increase in student confidence.

- "I feel/felt better prepared for the field"

- Pre-trip 69\%

- Post-trip 60\%

- "I found the virtual training a useful experience mapping"

- Pre-trip $80 \%$

- Post-trip $71 \%$ 


\section{Accessibility Benefits}

- Create alternative field trips for students with health/mobility issues.

- Hand specimens and thin sections, photographs.

- Assessment : Field report, map, cross section etc.

- More closely matches learning outcomes.

- "Hybrid trips": Recreate specific localities for students who can attend field trip but not reach every outcrop.

\section{OUTCROP DESCRIPTION:}

around at lot about the unconformity!

NOTES:

This outcrop is the contact between the underlying

Rock Type $D$ and the overlying Rock Type $H$

Photo: unconformity between Rock Type $D$ and

Rock Type H.

ATA:

Bedding: $015 / 02 E$

Foliation: $093 / 02 \mathrm{~N}$

Lithology (lower) : Rock Type D
Lithology (Upper) : Rock Type H

Debug - Rock-outcrop65Book
Looking north

Graded bedding Rock type H

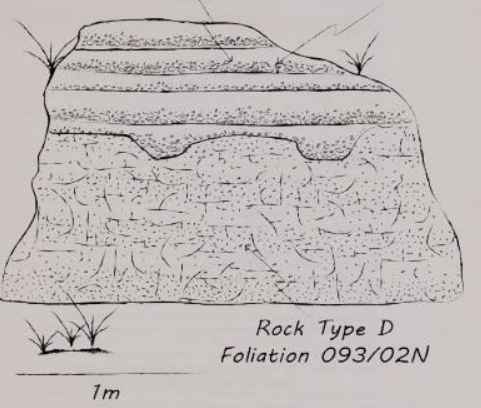

Unconformity between Rock Type $H$ and Rock Type

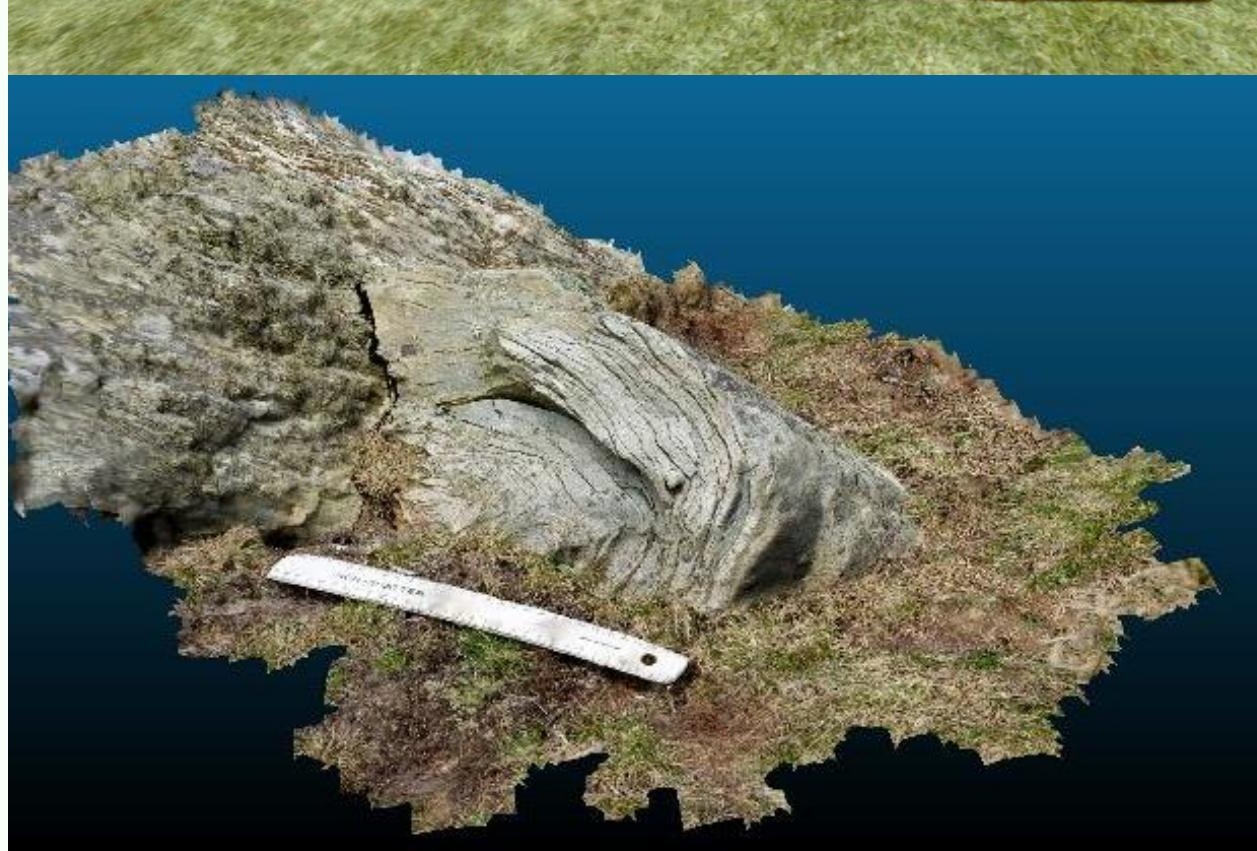




\section{Other worlds and future} plans

- More alternative and hybrid field trips.

- Site investigation type fieldwork.

- Interactive block models demonstrating outcrop patterns.

- Other subjects.

- Research.

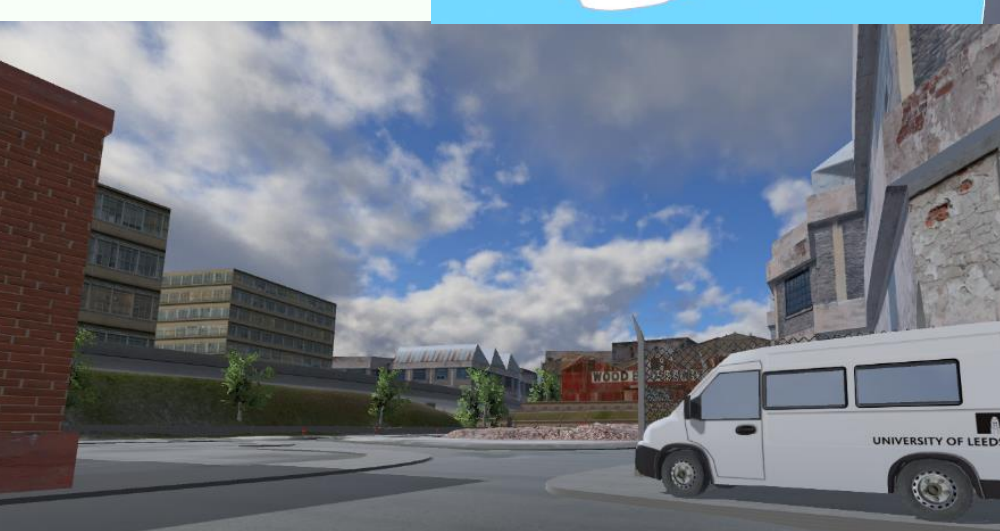




\section{Summary}

- Game-based training environments.

- Learn basic skills before going into the field.

- Develop 3D visualisation skills.

- Field skills training for those unable to access the field.

- Results:

- Increased confidence in field skills.

- Time saved in the field.

- Improved performance.

www.see.leeds.ac.uk/virtuallandscapes/ 


\section{UNIVERSITY OF LEEDS}

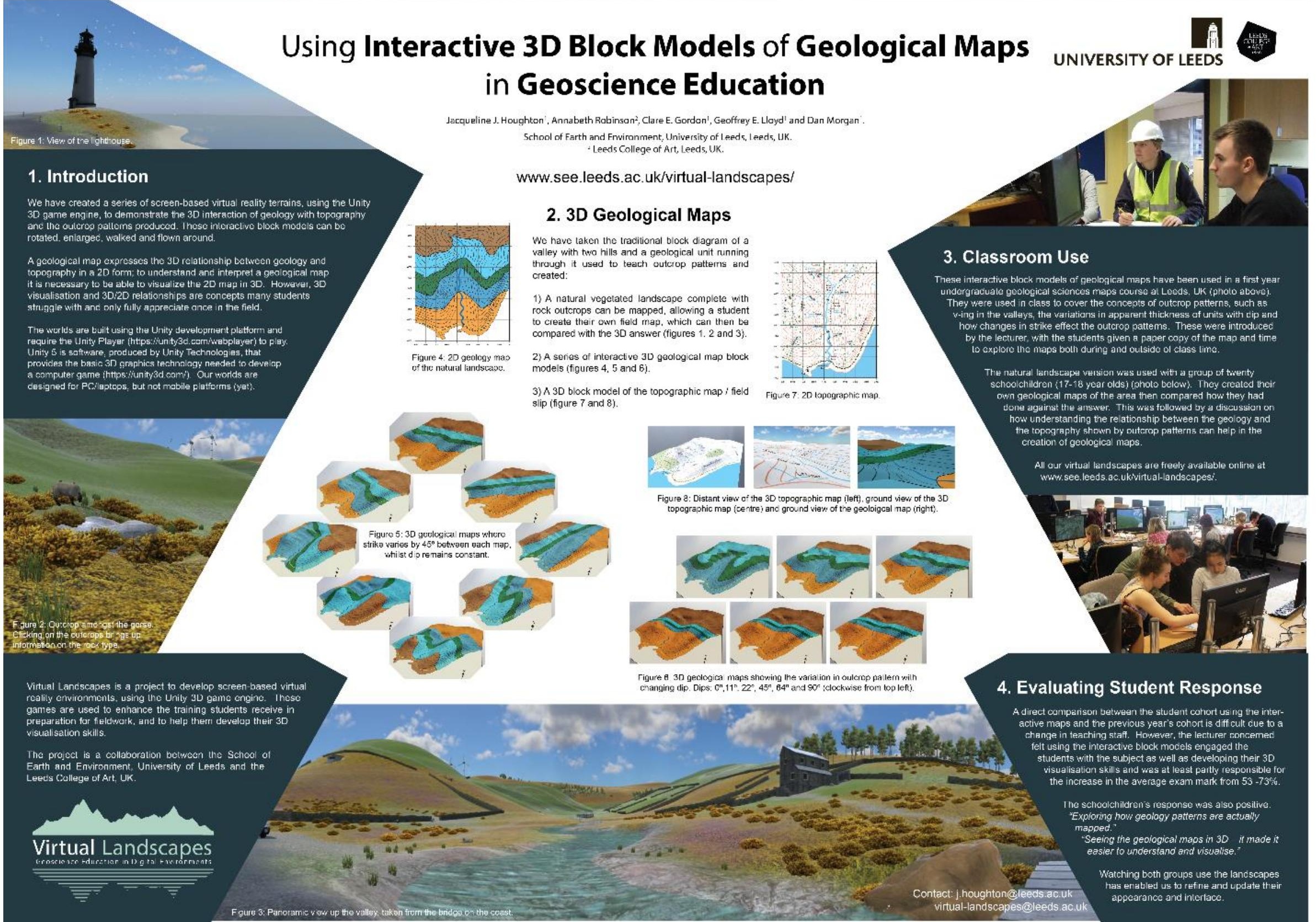

